\title{
Determinants of Successful Vaginal Birth After Caesarean Section at Public Hospitals in Ambo Town, Oromia Region, Central Ethiopia: A Case-Control Study
}

\author{
Firehiywot Teferi Mekonnin' \\ Gizachew Abdissa Bulto (iD) ${ }^{2}$ \\ 'Department of Obstetrics and \\ Gynecology, Ambo General Hospital, \\ Ambo, Ethiopia; ${ }^{2}$ Department of \\ Midwifery, College of Medicine and \\ Health Sciences, Ambo University, Ambo, \\ Ethiopia
}

Background: The World Health Organization recommends a caesarean section (CS) rate at health facilities from 10 to $15 \%$, but the rate is higher at most of the institutions in different countries, including Ethiopia resulting in negative health-related and economic consequences. Vaginal birth after caesarean section (VBAC) is a safe and appropriate choice to decrease the rate of CS. Though the success rate is $60-80 \%$, the number of mothers who experience the trial of labor is decreasing and the overall CS rate is rising. There is also limited information on determinants of successful VBAC in Ethiopia. Therefore, the study aimed to identify determinants of successful VBAC at public hospitals in Ambo town.

Methods: A Facility-based retrospective unmatched case-control study was employed at public hospitals in Ambo town, Ethiopia, from June 1 to July 1, 2020. A systematic random sampling technique was used to select cases $(n=74)$ and controls $(n=221)$. The data were collected using a structured questionnaire and it was filled IN by reviewing the client's medical record. The data were entered into Epi Info and exported to SPSS for analysis. Bivariate and multivariable logistic regression analysis was carried out for data analysis. Finally, statistical significance was determined based on the odds ratio with its $95 \%$ confidence interval and a p-value of $<0.05$.

Results: Mothers whose age was less than 25 years and 25-29 years (AOR: 8.88; 95\% CI 3.03, 26.03) and (AOR: 5.37 ; 95\% CI 2.28, 12.66), respectively, mothers who had a history of previous successful VBAC (AOR: 3.01; 95\% CI 1.47, 6.13), had a history of previous spontaneous vaginal delivery (AOR: $3.85 ; 95 \%$ CI $1.84,8.05$ ) and cervical dilation $\geq 4 \mathrm{~cm}$ at admission (AOR: 2.05: 95\% CI 1.14, 3.67) were independent determinants of successful VBAC.

Conclusion: The study identified that past and present obstetric conditions played a significant role in the success of VBAC. Therefore, health workers have to consider those predictors while counselling and choosing mothers for trial of labor after caesarean section (TOLAC).

Keywords: determinants, vaginal birth after caesarean section, Ambo town

\section{Background}

Globally, about $21.1 \%$ of women gave birth by caesarean section, which is distributed irregularly and ranges from 5\% in sub-Saharan Africa to $42.8 \%$ in Latin America and the Caribbean. The 2016 Ethiopian demographic and health survey found that $1.9 \%$ of women delivered by CS. Worldwide, the CS rate is projected to
Correspondence: Gizachew Abdissa Bulto

Email gizachab@yahoo.com 
be $28.5 \%$ by $20300^{1,2}$ Ethiopia's 2019 demographic and health survey showed that only $48 \%$ of births were in a health facility. ${ }^{3}$ The overall prevalence of caesarean section in Ethiopia among those who gave birth at the health institutions was $29.55 \%$, ranging from $11.03 \%$ to 63.75\%. ${ }^{4-9}$ But, the World Health Organization identifies that a CS rate above the ideal rate of $10-15 \%$ in any region has no justification and is unnecessary, which in turn leads to morbidity and mortality that is the result of CS. ${ }^{10}$ The main reason for this rise in CS rate is the decline of the rate of vaginal birth after caesarean section. ${ }^{11}$

Vaginal birth after caesarean section (VBAC) is a planned trial to give birth vaginally by a woman who has had a previous caesarean section. ${ }^{11}$ Candidates for a trial of labor are women with one previous caesarean section, low transverse hysterotomy and singleton pregnancy with no contra-indication for vaginal delivery. ${ }^{12}$ Choosing the route of delivery after one previous caesarean section depends on the mother's preferences, past and present obstetric history. ${ }^{12,13}$ The success rate of VBAC is $60-80 \%$ if the previous caesarean section is done for nonrecurring indications. ${ }^{12,14,15} \mathrm{~A}$ study in Addis Ababa showed that $69.4 \%$ of mothers had a successful VBAC. ${ }^{16}$ Moreover, VBAC is a safe and appropriate choice for most mothers with a prior CS. However, the number of mothers who experienced trial of labor after caesarean section (TOLAC) is decreasing, resulting in an overall rise in CS rate. ${ }^{11}$ VBAC is associated with fewer complications than planned repeated caesarean sections. The absolute risk of uterine rupture attributable to a trial of labor is low, that is, about 2.7 to 7 per $1000 .^{12,17}$

Even though considerable variations exist in the proportion of pregnant mothers who offer and attempt VBAC across centers, many authors report that three-quarters of pregnant mothers who try VBAC give birth vaginally. ${ }^{18}$ A different study revealed that a mother's expectations for birth and mode of birth preference are not influenced only by knowledge of the potential benefits and risks but also by the culture of the society, the availability of resources, the distance of the facility and obstetrician judgment. ${ }^{19-21}$ Studies have tried to address methods for identifying pregnant mothers at low and high risk of failure of an attempted VBAC but none of them has a validated tool. ${ }^{15,22}$

Caesarean section is overused once the mother has had birth by CS, which in turn increases the risk of maternal complications. However, VBAC is a safe option with low complications. So, TOLAC is a preferred method for pregnant mothers with no contra-indications for vaginal delivery. ${ }^{13,23,24}$ Furthermore, postpartum death is higher in mothers who deliver by CS than normal vaginal or instrumental delivery. Most maternal deaths are due to anesthesia complications, which is recorded with a mother who undergoes $\mathrm{CS}^{25,26}$

Therefore, VBAC has many more benefits than CS, starting from fulfilling the mothers' preference individually up to decreasing maternal morbidity and mortality, risk of complications in the next pregnancy and the rate of caesarean sections at a population level. ${ }^{11} \mathrm{~A}$ successful VBAC has fewer complications and many advantages. Those advantages are: it avoids abdominal surgery, decreases the risk of hemorrhage and infections, shortens the postpartum period and decreases possible complications that result from multiple caesarean sections like blood transfusion, hysterectomy, injury of bladder and bowel and abnormal placenta implantation. But a failed VBAC has more complications than a planned repeated caesarean section and successful VBAC. ${ }^{11,18}$

Although some studies were conducted in Ethiopia regarding the success of VBAC, there is a scarcity of evidence to identify determinants of successful VBAC. In addition to this, predicting the success of VBAC is a difficult task due to the absence of a clear predicting tool. If the determinants of successful VBAC are known or successfully designed, the hospitals, staff and clients work collaboratively to make the rate of CS low and the safest and appropriate VBAC higher. Therefore, this study was done to identify determinants of successful vaginal birth after caesarean section in public hospitals in Ambo town, Oromia regional state, central Ethiopia.

\section{Methods}

\section{Study Design, Area and Period}

A facility-based retrospective unmatched case-control study was conducted in Ambo town public hospitals from June 1 to July 1, 2020. Ambo is located in the West Shoa zone of the Oromia region, Ethiopia. Ambo is the capital city of the West Shoa zone, located 114 kilometers from Addis Ababa. According to the 2007 Ethiopian national census report, the total population in Ambo town was 108,406 . The town has two public hospitals, namely, Ambo University Referral Hospital and Ambo General Hospital, fully providing obstetric and gynecologic services. 


\section{Source Population and Study Population}

All records of mothers with previous caesarean section who attempted TOLAC at Ambo General and Ambo University Referral Hospitals from May 20, 2017 to April 20, 2020 were the source population. Cases were records of mothers with one previous caesarean section who were allowed TOLAC according to the protocol of the hospitals, whose labor started spontaneously and whose babies were delivered vaginally. Controls were records of mothers with one previous caesarean section who were allowed TOLAC according to the protocol of the hospitals, whose labor started spontaneously and whose babies were delivered by caesarean section after trial of labor. Mothers' records with incomplete and nonreadable data were excluded.

\section{Sample Size Determination and Sampling Technique}

The sample size was estimated by using a double population proportion formula using Epi Info version 7.2.2.6 stat calc for an unmatched case-control study with the assumptions of a $95 \%$ two-sided confidence level $(\mathrm{CI})$, power of $80 \%, 3: 1$ ratio of controls to cases, and $6.8 \%$ of prior successful VBAC among the controls exposed and odds ratio of 3.38 from the case-control study done in Addis Ababa, Ethiopia. ${ }^{18}$ Hence, the final sample size was found to be 296 , with 74 cases and 222 controls.

Initially, the sampling frame was developed for the cases and controls groups before the actual data collection period for the two hospitals. A total of 637 mothers had attempted TOLAC from May 20, 2017 to April 20, 2020 in the two hospitals. Then the distribution of mothers who gave birth was taken by proportionate allocation to size from the two public hospitals. Finally, a systematic random sampling technique was used to select the study participants. For both cases and controls groups, the first subject was determined randomly by lottery method and every second were used to select cases and controls.

\section{Operational Definition}

Trial of labor after caesarean (TOLAC): a planned attempt to labor by a mother who has had a previous caesarean delivery, regardless of the outcome. ${ }^{11}$

Successful VBAC: trial of labor after caesarean section resulting in vaginal delivery. ${ }^{27}$

Failed VBAC: trial of labor after previous caesarean section resulting in unplanned Intrapartum caesarean delivery. ${ }^{13}$

\section{Data Collection Tool and Techniques}

A structured questionnaire adapted from different researches with certain modifications was used to collect the data. ${ }^{18,28,29}$ The structured questionnaire which consisted of socio-demographic characteristics, reproductive history, past obstetrics and medical history and intrapartum history, prepared in English, was used for data collection. First, the card number of mothers who delivered by vaginal route (cases) from May 20, 2017 to April 20, 2020 were identified from the delivery registration book and mothers who attempted TOLAC but failed to deliver through vaginal route (controls) from May 20, 2017 to April 20, 2020 were identified from operation logbooks. Then, a structured pre-tested questionnaire was used to collect the required information through document review retrospectively. Four bachelor degree midwives who had at least two years of work experience were recruited as data collectors and two supervisors who have Masters of Sciences in Health supervised the data collection procedure.

\section{Data Quality Control and Management}

A pre-test was done on $5 \%{ }^{15}$ of the total study participants at Gedo General Hospital, which is found 78 kilometers to the west of Ambo town, a week before the actual data collection. After the pre-test, necessary adjustment was made on the questionnaire. Training for the data collectors and supervisors was given on the objective of the research, contents of tools, how to collect the data from the clients' charts and how to fill the questionnaires, and the completeness of the data. The quality of the data collected was assured by checking all filled questionnaires at the end of the day by the principal investigator and the supervisors. After the completeness of each questionnaire was checked, a unique code was given by the principal investigator.

\section{Data Processing and Analysis}

Data were coded and entered into Epi Info version 7.2.2.6, then exported to SPSS version 23. The data was cleaned, categorized and analysed using SPSS. Descriptive data were generated, including frequency, percent, mean and standard deviation. Cross-tabulation of independent variables with the success of VBAC was done and the findings were displayed using tables and graphs. A bivariate logistic regression analysis was done for all independent variables. Those variables with $p$-values less than 0.2 in bivariate analysis were taken and analysed in 
a multivariable logistic regression model to control the possible confounders. Variables at $p$-values of $\leq 0.05$ in the multivariable logistic regression model were considered statistically significant and an odds ratio with corresponding $95 \%$ CI was reported as the measure of the degree of association.

\section{Ethical Considerations}

The study was conducted in accordance with the Declaration of Helsinki. Ethical clearance was obtained from the Institutional Review Board of the College of Medicine and Health Sciences, Ambo University. A formal letter of support was obtained from the College of Medicine and Health Sciences to Ambo General and Ambo University Referral Hospitals and permission was obtained from each hospital's administration. As the current study involved collecting data from the patient file retrospectively, written informed consent was obtained from the hospital's administrator and this was also approved by the institutional review board of the College of Medicine and Health Sciences, Ambo University. The data was collected from the patient's file after tracing the client's medical record number. Furthermore, the confidentiality of the collected data was assured by giving a code for each medical record and hence their name was not recorded.

\section{Results}

\section{Socio-Demographic Characteristics of Study Participants}

Complete data was collected from a total of 295 participants, making a response rate of $100 \%$. The mean age of the study participants was 27 years, with a standard deviation of 3.345 among cases and 28 years with a standard deviation of 3.266 among controls. Nearly two-thirds $(62.2 \%)$ of cases and more than half (54.3\%) of controls were between the ages of $25-29$ years. About $56.8 \%$ of cases and nearly-two thirds (63.3\%) of controls were from urban residences. More than four-fifths (89.2\%) of cases and $90 \%$ of controls were married (Table 1).

\section{Reproductive History of Mothers}

Nearly half (47.3\%) and more than two-thirds (67.4\%) of women had a parity of two among cases and controls, respectively. More than four-fifths $(87.8 \%)$ of cases and (83.75\%) of controls had no abortion history. Thirty-one (41.9\%) cases and $91(41.2 \%)$ controls gave birth at term.
Table I Socio-Demographic and Reproductive Health-Related Characteristics of Mothers Who Had a Trial of Labor After Cesarean Section at Public Hospitals in Ambo Town, Oromia Regional State, Central Ethiopia, $2020(n=295)$

\begin{tabular}{|c|c|c|c|c|}
\hline Variables & Category & $\begin{array}{l}\text { Cases, } \\
74(\%)\end{array}$ & $\begin{array}{l}\text { Controls, } \\
221 \text { (\%) }\end{array}$ & p-value \\
\hline Age & $\begin{array}{l}<25 \\
25-29 \\
\geq 30\end{array}$ & $\begin{array}{l}15(20.2) \\
46(62.2) \\
13(17.6)\end{array}$ & $\begin{array}{l}33(14.9) \\
120(54.3) \\
68(30.8)\end{array}$ & 0.078 \\
\hline Residence & $\begin{array}{l}\text { Rural } \\
\text { Urban }\end{array}$ & $\begin{array}{l}32(43.2) \\
42(56.8)\end{array}$ & $\begin{array}{l}81(36.7) \\
140(63.3)\end{array}$ & 0.313 \\
\hline Marital status & $\begin{array}{l}\text { Married } \\
\text { Unmarried } \\
\text { Others* }\end{array}$ & $\begin{array}{l}66(89.2) \\
5(6.8) \\
3(4)\end{array}$ & $\begin{array}{l}199(90) \\
13(5.9) \\
9(4.1)\end{array}$ & 0.712 \\
\hline Parity & $\begin{array}{l}\text { II } \\
\text { III } \\
\geq I V\end{array}$ & $\begin{array}{l}35(47.3) \\
31(41.9) \\
8(10.8)\end{array}$ & $\begin{array}{l}149(67.4) \\
44(19.9) \\
28(12.7)\end{array}$ & 0.001 \\
\hline $\begin{array}{l}\text { Gestational age } \\
\text { in weeks }\end{array}$ & $\begin{array}{l}28-36^{+6} \\
37^{+0}-40^{+0} \\
>40^{+0} \\
\text { Unknown }\end{array}$ & $\begin{array}{l}0(0.0) \\
3 \mid(4 \mid .9) \\
13(\mid 7.6) \\
30(40.5)\end{array}$ & $\begin{array}{l}3(1.4) \\
91(41.2) \\
67(30.3) \\
60(27.1)\end{array}$ & 0.05 \\
\hline Abortion & $\begin{array}{l}\text { Yes } \\
\text { No }\end{array}$ & $\begin{array}{l}9(12.2) \\
65(87.8)\end{array}$ & $\begin{array}{l}36(16.3) \\
185(83.7)\end{array}$ & 0.393 \\
\hline $\begin{array}{l}\text { Antenatal care } \\
\text { follow-up }\end{array}$ & $\begin{array}{l}\text { Booked } \\
\text { Not } \\
\text { booked }\end{array}$ & $\begin{array}{l}66(89.2) \\
8(10.8)\end{array}$ & $\begin{array}{l}204(92.3) \\
17(7.7)\end{array}$ & 0.404 \\
\hline
\end{tabular}

Notes: *Divorced, widowed.

The majority (89.2\%) of cases and $92.3 \%$ of controls had antenatal care visits for their last pregnancy (Table 1).

\section{Past Obstetric and Medical History Related Characteristics}

Out of the total participants, 53 (71.6\%) cases and 185 $(83.7 \%)$ controls had no previous successful VBAC. Nearly two-thirds $(67.6 \%)$ of cases and more than threequarters $(79.6 \%)$ of controls had no past spontaneous vaginal delivery (SVD). Regarding medical problems, the majority of cases $(97.3 \%)$ and controls (96.4\%) had no medical problems (Table 2).

\section{Indications for Past Caesarean Section}

The study showed that the chance of successful VBAC was high in mothers whose indication for past caesarean section was fetal distress: $21(28.4 \%)$ cases and 44 (19.9\%) controls. This was followed by malpresentation: $13(17.6 \%)$ cases and 30 (13.6\%) controls (Figure 1). 
Table 2 Past and Present Obstetric and Newborn Related Characteristics of Study Participants at Public Hospitals, in Ambo Town, Oromia Regional State, Central Ethiopia, 2020 $(n=295)$

\begin{tabular}{|c|c|c|c|}
\hline Variables & Category & $\begin{array}{l}\text { Cases, } \\
74 \text { (n \%) }\end{array}$ & $\begin{array}{l}\text { Controls, } \\
22 \text { I (n \%) }\end{array}$ \\
\hline Previous successful VBAC & $\begin{array}{l}\text { Yes } \\
\text { No }\end{array}$ & $\begin{array}{l}21(28.4) \\
53(71.6)\end{array}$ & $\begin{array}{l}36(16.3) \\
185(83.7)\end{array}$ \\
\hline No. of successful VBAC & $\begin{array}{l}1 \\
2\end{array}$ & $\begin{array}{l}19(90.5) \\
2(9.5)\end{array}$ & $\begin{array}{l}30(83.3) \\
6(16.7)\end{array}$ \\
\hline $\begin{array}{l}\text { Past SVD } \\
\text { No. of SVD }\end{array}$ & $\begin{array}{l}\text { Yes } \\
\text { No } \\
\text { Only once } \\
\geq 2\end{array}$ & $\begin{array}{l}24(32.4) \\
50(67.6) \\
20(83.3) \\
4(16.7)\end{array}$ & $\begin{array}{l}45(20.4) \\
176(79.6) \\
30(66.7) \\
15(33.3)\end{array}$ \\
\hline History of stillbirth & $\begin{array}{l}\text { Yes } \\
\text { No }\end{array}$ & $\begin{array}{l}3(4.1) \\
71(95.9)\end{array}$ & $\begin{array}{l}20(9.0) \\
201(91.0)\end{array}$ \\
\hline Had medical problem & $\begin{array}{l}\text { Yes } \\
\text { No }\end{array}$ & $\begin{array}{l}2(2.2) \\
72(97.3)\end{array}$ & $\begin{array}{l}8(3.6) \\
213(96.4)\end{array}$ \\
\hline $\begin{array}{l}\text { Membrane status at } \\
\text { admission }\end{array}$ & $\begin{array}{l}\text { Intact } \\
\text { Ruptured }\end{array}$ & $\begin{array}{l}34(45.9) \\
40(54.1)\end{array}$ & $\begin{array}{l}135(61.1) \\
86(38.9)\end{array}$ \\
\hline $\begin{array}{l}\text { Duration of rupture of } \\
\text { membrane at admission }\end{array}$ & $\begin{array}{l}<8 \text { hours } \\
\geq 8 \text { hours }\end{array}$ & $\begin{array}{l}37(92.5) \\
3(7.5)\end{array}$ & $\begin{array}{l}78(90.7) \\
8(9.3)\end{array}$ \\
\hline Type of amniotic fluid & $\begin{array}{l}\text { Clear } \\
\text { Bloody } \\
\text { Meconium }\end{array}$ & $\begin{array}{l}25(62.5) \\
4(10.0) \\
I I(27.5)\end{array}$ & $\begin{array}{l}48(55.8) \\
8(9.3) \\
30(34.9)\end{array}$ \\
\hline $\begin{array}{l}\text { Dilation of cervix at } \\
\text { admission }\end{array}$ & $\begin{array}{l}<4 \mathrm{~cm} \\
\geq 4 \mathrm{~cm}\end{array}$ & $\begin{array}{l}28(37.8) \\
46(62.2)\end{array}$ & $\begin{array}{l}120(54.3) \\
101(45.7)\end{array}$ \\
\hline Grade of meconium & $\begin{array}{l}\text { Grade I } \\
\text { Grade II } \\
\text { Grade III }\end{array}$ & $\begin{array}{l}7(63.6) \\
2(18.2) \\
2(18.2)\end{array}$ & $\begin{array}{l}\mathrm{II}(36.7) \\
10(33.3) \\
9(30.0)\end{array}$ \\
\hline Duration of labor & $\begin{array}{l}\leq 4 \text { hours } \\
>4 \text { hours }\end{array}$ & $\begin{array}{l}18(24.3) \\
56(75.7)\end{array}$ & $\begin{array}{l}30(13.6) \\
191(86.4)\end{array}$ \\
\hline Baby born alive & $\begin{array}{l}\text { Yes } \\
\text { No }\end{array}$ & $\begin{array}{l}72(97.3) \\
2(2.7)\end{array}$ & $\begin{array}{l}213(96.4) \\
8(3.6)\end{array}$ \\
\hline First Apgar score & $\begin{array}{l}0-3 \\
4-6 \\
7-10\end{array}$ & $\begin{array}{l}I(1.4) \\
10(13.5) \\
63(85.1)\end{array}$ & $\begin{array}{l}7(3.2) \\
65(29.4) \\
149(67.4)\end{array}$ \\
\hline Fifth Apgar score & $\begin{array}{l}0-3 \\
4-6 \\
7-10\end{array}$ & $\begin{array}{l}2(2.7) \\
0(0.0) \\
72(97.3)\end{array}$ & $\begin{array}{l}8(3.6) \\
16(7.3) \\
197(89.1)\end{array}$ \\
\hline Birth weight in gram & $\begin{array}{l}<2500 \\
2500- \\
4000 \\
>4000\end{array}$ & $\begin{array}{l}7(9.5) \\
64(86.5) \\
3(4.0)\end{array}$ & $\begin{array}{l}9(4.1) \\
205(92.8) \\
7(3.1)\end{array}$ \\
\hline
\end{tabular}

\section{Current Obstetric and Fetal Factors}

Regarding membrane status at admission, nearly half $(45.9 \%)$ of cases and $61.1 \%$ of controls had intact membranes. Nearly three-quarters $(75.7 \%)$ of cases and greater than four-fifths $(86.4 \%)$ of controls had greater than four hours labor stay after admission. The majority of newborns, that is, 64 cases (86.5\%) and 205 controls (92.8\%) had 2500 to $4000 \mathrm{~g}$ birth weight. An initial pelvic examination was conducted at the time of admission; of women attempting VBAC, a $\geq 4 \mathrm{~cm}$ dilation was recorded for 46 cases $(62.2 \%)$ and 101 controls $(45.7 \%)$ (Table 2).

Out of 74 cases, more than two-thirds $(70.3 \%)$ of mothers delivered through spontaneous vaginal delivery while nearly one-third (29.7\%) of them delivered through instrumental delivery. Regarding emergency repeat caesarean section, non-progress of labor $(85,38.9 \%)$ was the common indication, followed by fetal distress $(58,25.3 \%)$ and cervical arrest $(28,12.7 \%)$ (Figure 2).

\section{Determinants of Successful Vaginal Birth After Caesarean Section}

In bivariate logistic regression analysis, maternal age, parity, previous successful VBAC, previous SVD, membrane status at admission, cervical dilation at admission and duration of labor stay after admission were significantly associated with the success of VBAC. From the multivariable logistic regression analysis, maternal age, previous successful VBAC, previous SVD and cervical dilation at admission were significantly associated with the success of VBAC.

In the present study, the odds of having successful VBAC were nearly nine and five times higher among those mothers aged less than 25 years and 25-29 years (AOR: 8.88; 95\% CI 3.03, 26.03) and (AOR: 5.37; 95\% CI $2.28,12.66$ ), respectively, than those aged $\geq 30$ years. The odds of having successful VBAC were three times higher among mothers with previous successful VBAC after previous CS (AOR: 3.01; 95\% CI 1.47, 6.13) compared to their counterparts. Similarly, mothers with a history of previous spontaneous vaginal delivery before the past CS have a 3.85 times higher odds of having successful VBAC compared to mothers who had no past spontaneous vaginal delivery (AOR: 3.85 ; 95\% CI 1.84 , 8.05). The odds of having successful VBAC were twice as high among mothers with cervical dilation of $\geq 4 \mathrm{~cm}$ at 


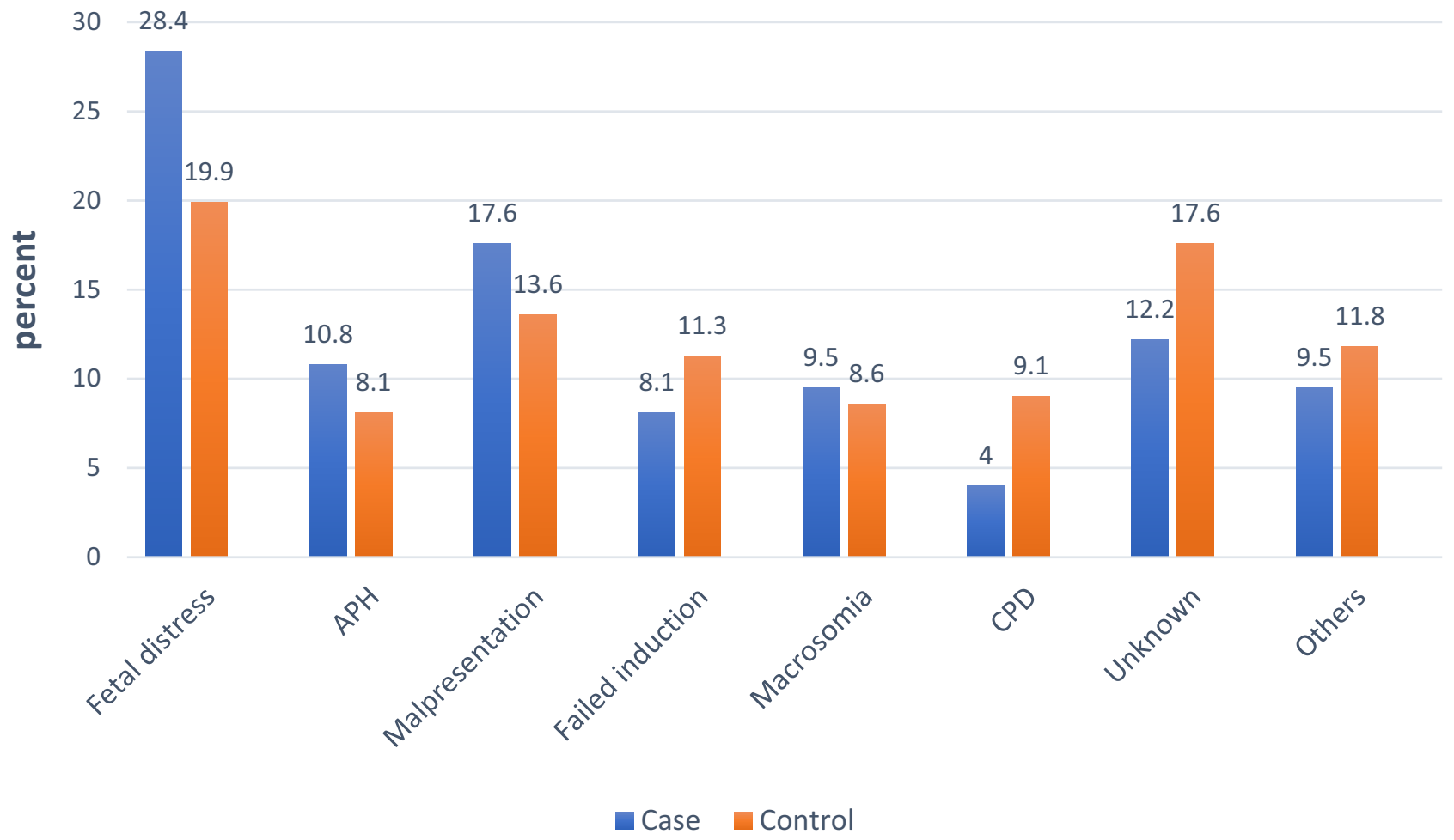

Figure I Shows indication of past caesarean section in mothers with trail labor at public hospitals, in Ambo town, Oromia regional state, Central Ethiopia, 2020 ( $\mathrm{n}=295$ ).

Indication for emergency repeat caesarean section

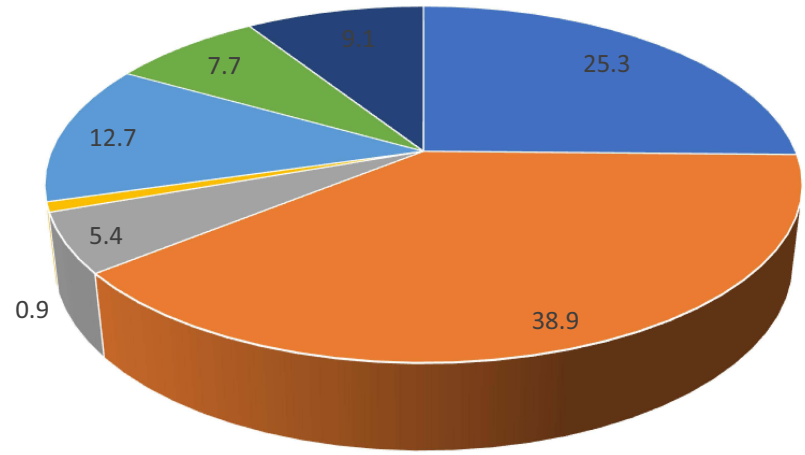

\begin{tabular}{|c|c|c|}
\hline - Fetal distress & - Non progress of labor & - Scar tenderness \\
\hline APH & - Cervical arrest & - Malposition/malpresentation \\
\hline
\end{tabular}

Figure 2 Shows the indication of emergency repeat caesarean section in mothers who trail labor at public hospitals, in Ambo town, Oromia regional state, Central Ethiopia, $2020(n=295)$. 
admission than those with cervical dilation of $<4 \mathrm{~cm}$ at admission (AOR: 2.05: 95\% CI 1.14, 3.67) (Table 3).

\section{Discussion}

This study identified determinants of successful vaginal birth after caesarean section at public hospitals in Ambo town, Oromia regional state, Central Ethiopia. The current study found that the age of the mothers was one of the important predicting factors for the success of VBAC. The odds of having successful VBAC were nearly nine and five times higher among those mothers aged less than 25 years and 25-29 years, respectively, compared to those aged $\geq 30$ years. This is consistent with studies conducted in India ${ }^{30,31}$ and the United States of America. ${ }^{15}$ This might be because mothers of advanced age might be less likely to attempt VBAC and it is more likely to fail when attempted. This finding is also supported by the studies done by Srinivas et al and $\mathrm{Wu}$ et al. ${ }^{32,33}$ In addition, medical problems like chronic hypertension and diabetes mellitus increase with age and this in turn increases the failure rate. ${ }^{33}$ The rate of VBAC-related operative complications also increases as maternal age increases. ${ }^{32}$
The present study also indicated that previous successful VBAC is significantly associated with the current success of VBAC. The odds of having successful VBAC were three times among mothers with previous successful VBAC after the past CS compared to their counterparts. This finding is in agreement with previous studies conducted in Ethiopia, ${ }^{18}$ Nigeria, ${ }^{28}$ the United States of America, ${ }^{15}$ and New Zealand. ${ }^{34}$ This might indicate that a previous successful VBAC shortens the progress of labor and lowers the risk of subsequent rupture of the uterus and other morbidities. $^{35}$

This study revealed that history of previous spontaneous vaginal delivery was an independent determinant factor of successful VBAC. Mothers with a history of previous spontaneous vaginal delivery before a the past CS have nearly four times higher odds of having successful VBAC compared to mothers who had no past spontaneous vaginal delivery. This is consistent with studies from Nigeria, ${ }^{28}$ Anatolia, $^{20}$ Bahrain $^{35}$ and New Zealand. $^{34}$ This might be due to those mothers who had the previous CS for the reason of non-recurrent causes. Another justification for this is that previous vaginal

Table 3 Bivariate and Multivariable Logistic Regression Analysis Showing Determinants of Successful Vaginal Birth After Caesarean Section at Public Hospitals in Ambo Town, Oromia Regional State, Central Ethiopia 2020

\begin{tabular}{|c|c|c|c|c|c|}
\hline \multirow[t]{2}{*}{ Variable } & \multirow[t]{2}{*}{ Category } & \multicolumn{2}{|c|}{ Success of VBAC } & \multirow[t]{2}{*}{ COR $(95 \% \mathrm{Cl})$} & \multirow[t]{2}{*}{ AOR $(95 \% \mathrm{Cl})$} \\
\hline & & Cases, 74(\%) & Controls, 221 (\%) & & \\
\hline Age & $\begin{array}{l}<25 \\
25-29 \\
\geq 30\end{array}$ & $\begin{array}{l}15(20.2) \\
46(62.2) \\
13(17.6)\end{array}$ & $\begin{array}{l}33(14.9) \\
120(54.3) \\
68(30.8)\end{array}$ & $\begin{array}{l}2.378(1.015-5.569) \\
2.005(1.012-3.973) \\
I\end{array}$ & $\begin{array}{l}8.88(3.03-26.03) * * * \\
5.37(2.28-12.66) * * * \\
1\end{array}$ \\
\hline Parity & $\begin{array}{l}\text { III } \\
\geq \mathrm{IV} \\
\text { II }\end{array}$ & $\begin{array}{l}31(4 I .9) \\
8(10.8) \\
35(47.3)\end{array}$ & $\begin{array}{l}44(19.9) \\
28(12.7) \\
149(67.4)\end{array}$ & $\begin{array}{l}2.999(1.665-5.405) \\
1.216(0.5 \mathrm{I} I-2.897) \\
\mathrm{I}\end{array}$ & $\begin{array}{l}0.72(0.10-5.17) \\
0.18(0.007-4.63) \\
\mathrm{I}\end{array}$ \\
\hline Previous successful VBAC & $\begin{array}{l}\text { Yes } \\
\text { No }\end{array}$ & $\begin{array}{l}21(28.4) \\
53(71.6)\end{array}$ & $\begin{array}{l}36(16.3) \\
185(83.7)\end{array}$ & $\begin{array}{l}2.036(1.097-3.780) \\
\text { I }\end{array}$ & $\begin{array}{l}3.01(1.47-6.13) * * \\
1\end{array}$ \\
\hline SVD before CS & $\begin{array}{l}\text { Yes } \\
\text { No }\end{array}$ & $\begin{array}{l}24(32.4) \\
50(67.6)\end{array}$ & $\begin{array}{l}45(20.4) \\
176(79.6)\end{array}$ & $\begin{array}{l}\mathrm{I} .877(1.044-3.375) \\
\mathrm{I}\end{array}$ & $\begin{array}{l}3.85(1.84-8.05) * * * \\
\mathrm{I}\end{array}$ \\
\hline Membrane status & $\begin{array}{l}\text { Ruptured } \\
\text { Intact }\end{array}$ & $\begin{array}{l}40(54.1) \\
34(45.9)\end{array}$ & $\begin{array}{l}86(38.9) \\
135(61.1)\end{array}$ & $\begin{array}{l}1.847(1.086-3.14 \mid) \\
\mathrm{I}\end{array}$ & $\begin{array}{l}\text { I.38(0.75-2.55) } \\
\mathrm{I}\end{array}$ \\
\hline Cervical dilation & $\begin{array}{l}\geq 4 \mathrm{~cm} \\
<4 \mathrm{~cm}\end{array}$ & $\begin{array}{l}46(62.2) \\
28(37.8)\end{array}$ & $\begin{array}{l}101(45.7) \\
120(54.3)\end{array}$ & $\begin{array}{l}1.952(1.138-3.347) \\
\mathrm{I}\end{array}$ & $\begin{array}{l}2.05(1.14-3.67) * \\
I\end{array}$ \\
\hline Duration of labor & $\begin{array}{l}\leq 4 \mathrm{hrs} \\
>4 \mathrm{hrs}\end{array}$ & $\begin{array}{l}18(24.3) \\
56(75.7)\end{array}$ & $\begin{array}{l}30(13.6) \\
191(86.4)\end{array}$ & $\begin{array}{l}2.046(1.062-3.943) \\
\text { I }\end{array}$ & $\begin{array}{l}1.27(0.56-2.89) \\
\mathrm{I}\end{array}$ \\
\hline
\end{tabular}

Notes: I $=$ reference, $*_{p}<0.05 * *_{p}<0.01 * * * p<0.001$.

Abbreviations: COR, crude odds ratio; AOR, adjusted odds ratio. 
delivery is associated with more rapid labor and associated with a reduced risk of uterine rupture. ${ }^{12}$

The finding of this study shows that the odds of having successful VBAC were two times higher among mothers with cervical dilation of $\geq 4 \mathrm{~cm}$ at admission than those with cervical dilation of $<4 \mathrm{~cm}$. This finding is supported by studies done in Ethiopia, ${ }^{18}$ Anatolia $^{20}$ and Bahrain. ${ }^{35}$ The possible justification might be that once the mothers are in the active phase of labor they might be progressing to full dilation much more rapidly, with faster progress of labor. ${ }^{36}$

The implications of this study for obstetric care providers and hospitals are that past and present obstetric conditions were found to determine the success of VBAC. Therefore, those determinants should be considered during counselling and optimal selection of mothers for a trial of labor after CS which might have a higher success rate. The limitation of the current study is the use of a retrospective design, in which some of the important information which can be collected prospectively is missed.

\section{Conclusions}

The study identified past and present obstetric conditions that played a significant role in the success of VBAC.

Therefore, we recommend that hospitals and obstetric care providers should emphatically consider mothers with a history of vaginal delivery after or before previous CS, cervical dilation greater than or equal to $4 \mathrm{~cm}$ at admission and the young age of mothers as successful determinants for choosing women to trial labor after CS during counselling and optimal selection to avert the increasing rate of CS and its associated morbidities and mortalities. Additionally, conducting a further study using prospectively collected data or longitudinal studies was recommended.

\section{Abbreviations}

CS, cesarean section; VBAC, vaginal birth after cesarean section; SVD, spontaneous vaginal delivery; TOLAC, trial of labor after caesarean section.

\section{Data Sharing Statement}

The datasets used in the current study can be accessed from the corresponding author upon reasonable request.

\section{Acknowledgments}

We would like to thank Ambo University College of Medicine and Health Sciences, Department of Midwifery for the opportunity and Ambo town public hospitals for their cooperation during data collection. We also express our sincere gratitude to the staff of the public hospitals in Ambo town for their support.

\section{Funding}

No funding was received for this study.

\section{Disclosure}

The authors declare that they have no conflicts of interest for this work.

\section{References}

1. Betran AP, Ye J, Moller AB, Souza JP, Zhang J. Trends and projections of caesarean section rates: global and regional estimates: global and regional estimates. BMJ Glob Health. 2021;6(6):e005671. doi:10.1136/bmjgh-2021-005671

2. ICF CSACEa. Ethiopia Demographic and Health Survey 2016. The DHS Program ICF; 2017.

3. ICF EPHIEEa. Ethiopia Mini Demographic and Health Survey 2019: Key Indicators. 2019.

4. Getaneh T, Negesse A, Dessie G. Prevalence of surgical site infection and its associated factors after cesarean section in Ethiopia: systematic review and meta-analysis. BMC Pregnancy Childbirth. 2020;20 (1):1-11. doi:10.1186/s12884-020-03005-8

5. Tsegaye H. Prevalence of Caesarean Section and Associated Factors in Addis Ababa Hospitals, Addis Ababa, Ethiopia, 2017. Addis Ababa University; 2017.

6. Wondie AG, Zeleke AA, Yenus H, Tessema GA. Cesarean delivery among women who gave birth in Dessie Town Hospitals, Northeast Ethiopia. PLoS One. 2019;14(5):e0216344. doi:10.1371/journal. pone. 0216344

7. Tenaw Z, Kassa ZY, Kassahun G, Ayenew A. Maternal preference, mode of delivery and associated factors among women who gave birth at public and private hospitals in Hawassa City, Southern Ethiopia. Ann Glob Health. 2019;85(1). doi:10.5334/aogh.2578

8. Yenit M, Gezahegn T, Adefires M, Shiferaw A. Cesarean section rate, maternal and fetal outcome of birth following cesarean section at Finoteselam Hospital, Northwest Ethiopia: a descriptive retrospective data. Glob J Med Res. 2016;16(3):23-29.

9. Ayodeji Olanipekun MA. Prevalence of caesarean section and the associated factors in private hospitals in Addis Ababa-a Cross-Sectional Study [Thesis dissertation]. Addis Abeba Universty; 2017.

10. Betrán AP, Torloni MR, Zhang -J-J, Gülmezoglu A, Aleem H,; WHO statement on caesarean section rates. BJOG. 2016;123 (5):667-670. doi:10.1111/1471-0528.13526

11. Bulletins-Obstetrics CoP. ACOG practice bulletin no. 205: vaginal birth after cesarean delivery. Obstet Gynecol. 2019;133(2):110-127. doi:10.1097/AOG.0000000000003078

12. Cunningham F, Leveno K, Bloom S, Spong CY, Dashe J. Williams Obstetrics. 25 ed. Cunningham FG, Leveno KJ, Bloom SL. et al. editors. McGraw-hill; 2014.

13. MetzTD. Choosing the route of delivery after caeserean birth. UpToDate. Available from: https://www.uptodate.com/contents/choos ing-the-route-of-delivery-after-cesarean-birth. Accessed September 27, 2021.

14. Aram Thapsamuthdechakorn RS, Tongsong T, Tongsong T. Factors associated with successful trial of labor after cesarean section: a Retrospective Cohort Study. J Pregnancy. 2018;2018:1-5. doi:10.1155/2018/6140982

15. Tessmer-Tuck JA, El-Nashar SA, Racek AR, Lohse CM, Famuyide AO, Wick MJ. Predicting vaginal birth after cesarean section: a Cohort Study. Gynecol Obstet Invest. 2014;77 (2):121-126. doi:10.1159/000357757 
16. Misgan E, Gedefaw A, Negash S, Asefa A. Validation of a vaginal birth after cesarean delivery prediction model in teaching hospitals of Addis Ababa University: a Cross-Sectional Study. Biomed Res Int. 2020;2020. doi:10.1155/2020/1540460

17. Guise J-M, McDonagh MS, Osterweil P, Nygren P, Chan BK, Helfand M. Systematic review of the incidence and consequences of uterine rupture in women with previous caesarean section. BMJ. 2004;329(7456):19. doi:10.1136/bmj.329.7456.19

18. Birara M, Gebrehiwot Y. Factors associated with success of vaginal birth after one caesarean section (VBAC) at three teaching hospitals in Addis Ababa, Ethiopia: a Case Control Study. BMC Pregnancy Childbirth. 2013;13(1):31. doi:10.1186/1471-2393-13-31

19. Mu Y, Li X, Zhu J, et al. Prior caesarean section and likelihood of vaginal birth, 2012-2016, China. Bull World Health Organ. 2018;96 (8):548. doi:10.2471/BLT.17.206433

20. Senturk MB, Cakmak Y, Atac H, Budak MS. Factors associated with successful vaginal birth after cesarean section and outcomes in rural area of Anatolia. Int $J$ Womens Health. 2015;7:693. doi:10.2147/ IJWH.S83800

21. Iyoke C, Ugwu G, Ezugwu F, Lawani O, Onah H. Risks associated with subsequent pregnancy after one caesarean section: a Prospective Cohort Study in a Nigerian obstetric population. Niger J Clin Pract. 2014;17(4):442-448. doi:10.4103/1119-3077.134035

22. Li Y-X, Bai Z, Long D-J, et al. Predicting the success of vaginal birth after caesarean delivery: a retrospective cohort study in China. BMJ Open. 2019;9(5):e027807. doi:10.1136/bmjopen-2018-027807

23. Mascarello KC, Horta BL, Silveira MF. Maternal complications and cesarean section without indication: systematic review and meta-analysis. Rev Saude Publica. 2017;51:105.

24. Obstetricians RCo. Gynaecologists. Birth after previous caesarean birth. Green Top Guidel No. 2015;45:2015.

25. Subedi S. Rising rate of cesarean section-a year review. J Nobel Med Coll. 2011;1(2):50-56. doi:10.3126/jonmc.v1i2.7303

26. Yamuna R. A Comparitive Study of Indications and Fetomaternal Outcomes in Primary Cesarean Section in Primi and Multi Gravida. Government Mohan Kumaramangalam Medical College, Salem; 2018 .
27. Sudha C, Raksha B, Veena J, Rekha W. Obstetric outcome in vaginal birth after previous caesarean pregnancy (VBAC). J Evol Med Dent Sci. 2013;2(19):3198-3202. doi:10.14260/jemds/683

28. Eleje GU, Okam PC, Okaforcha EI, Anyaoku CS. Rates and determinants of successful vaginal birth after a previous caesarean section: a Prospective Cohort Study. ARC J Gynecol Obstet. 2019;4:1-8.

29. Minh T, Phuoc H. The success rate and associate factors of vaginal birth after cesarean section at $\mathrm{Tu} \mathrm{Du}$ Hospital in Vietnam. Int J Pregnancy Child Birth. 2018;4(3):129-133.

30. Madhavi V, Sapna S, Lavanya V, Sushma M. Factors associated with successful vaginal birth after Caeserean. Glob J Med Res. 2014;13(2):6.

31. Maurya A, Manik A. Original Research Article Study of factors associated with success of vaginal birth after previous one caesarean section. BMC Pregnancy Childbirth. 2013;13(1):1-6.

32. Srinivas SK, Stamilio DM, Sammel MD, et al. Vaginal birth after caesarean delivery: does maternal age affect safety and success? Paediatr Perinat Epidemiol. 2007;21(2):114-120. doi:10.1111/ j.1365-3016.2007.00794.x

33. Wu Y, Kataria Y, Wang Z, Ming W-K, Ellervik C. Factors associated with successful vaginal birth after a cesarean section: a systematic review and meta-analysis. BMC Pregnancy Childbirth. 2019;19 (1):1-12. doi:10.1186/s12884-019-2517-y

34. van der Merwe A-M, Thompson JM, Ekeroma AJ. Factors affecting vaginal birth after caesarean section at Middlemore Hospital, Auckland, New Zealand. N Z Med J. 2013;126(1383):49-57.

35. Alani WY, Part AB, Dayoub N. Factors influencing successful vaginal birth after cesarean delivery. Bahrain Med Bull. 2017;39(1):24-28.

36. Nicholas SS, Orzechowski KM, Berghella V, Baxter JK. Second trimester cervical length and its association with vaginal birth after cesarean delivery. Am J Perinatol. 2016;2(1):20-23.
Risk Management and Healthcare Policy

\section{Publish your work in this journal}

Risk Management and Healthcare Policy is an international, peerreviewed, open access journal focusing on all aspects of public health, policy, and preventative measures to promote good health and improve morbidity and mortality in the population. The journal welcomes submitted papers covering original research, basic science, clinical \& epidemiological studies, reviews and evaluations, guidelines, expert opinion and commentary, case reports and extended reports. The manuscript management system is completely online and includes a very quick and fair peer-review system, which is all easy to use. Visit http://www.dovepress.com/testimonials.php to read real quotes from published authors. 